\title{
Future of bisphosphonates and denosumab for men with advanced prostate cancer
}

\author{
This article was published in the following Dove Press journal: \\ Cancer Management and Research \\ 3 May 2014 \\ Number of times this article has been viewed
}

\author{
Maryam Iranikhah \\ Steve Stricker \\ Maisha Kelly Freeman \\ Samford University, McWhorter \\ School of Pharmacy, Birmingham, \\ AL, USA
}

Correspondence: Maryam Iranikhah Samford University, McWhorter School of Pharmacy 800 Lakeshore Drive, Birmingham, AL 35229, USA

Tel +l 2057262086

Fax + I 2057262669

Email miranikh@samford.edu

\begin{abstract}
Prostate cancer is the most common cancer occurring in American men of all races. It is also the second leading cause of cancer death among men in the USA. Bone metastasis is a frequent occurrence in men with advanced prostate cancer, with skeletal-related events being a common complication and having negative consequences, leading to severe pain, increased health care costs, increased risk of death, and decreased quality of life for patients. Bone loss can also result from antiandrogen therapy, which can further contribute to skeletal-related events. Treatment with antiresorptive agents bisphosphonates, and the newly approved denosumab, a receptor activator of nuclear factor kappa-B ligand (RANK-L) inhibitor, has been shown to reduce the risk of skeletal-related complications and prevent treatment-induced bone loss in patients with advanced prostate cancer. This review discusses the role of antiresorptive agents bisphosphonates and RANK-L inhibitor in the current treatment of advanced prostate cancer by examining the primary literature and also focuses on the likely role of the bisphosphonates in the treatment of advanced prostate cancer in the future.
\end{abstract}

Keywords: prostate cancer, bisphosphonates, skeletal-related events, RANK-L inhibitor, malignancy

\section{Introduction}

According to the Centers for Disease Control and Prevention and the National Cancer Institute, prostate cancer is the most common cancer in men of all races and the second leading cause of cancer death among men in the USA. In 2014, approximately 233,000 prostate cancer diagnoses and 29,480 deaths among American men are projected. ${ }^{1-3}$ Most cases of advanced prostate cancer result in bone metastasis. ${ }^{4}$ Skeletal-related events (SREs) due to bone metastasis are a common source of complications in malignancy and contribute to an increase in morbidity and mortality. ${ }^{5}$ These include pathologic fractures, spinal cord compression, hypercalcemia of malignancy, bone pain/lesions requiring palliative radiotherapy, and surgery for prevention and treatment of fractures. ${ }^{5,6}$ The aim of treating bone metastasis is to prevent/reduce the complications of SREs, thus improving patients' quality of life and functional independence. ${ }^{7}$ Hormonal therapy is the mainstay of treatment for metastatic prostate cancer. Antiandrogen therapy, which is the cornerstone of treatment, causes bone loss and reduces bone mineral density (BMD), which further increases the risk of SREs. In addition, bone health is impacted by cancer treatment, and treatment-related bone loss may lead to development of osteopenia or osteoporosis and its complications, including fractures and further pain. Managing bone health is important, given that osteoporosis and the associated increase in risk of bone fracture is a major health issue for cancer patients that will further affect their quality 
of life. The morbidity and mortality associated with bone loss can be prevented by appropriate screening, lifestyle interventions, and antiresorptive therapy. Antiandrogen therapy and the steroids that are used supportively in the treatment of cancer, combined with some clinical factors such as age, prior fracture history, and family history of fracture, further increase the risk of fracture in these patients. According to the National Comprehensive Cancer Network, it is recommended to screen men who are to be on androgen deprivation therapy (ADT) or steroids for osteoporosis as outlined in the National Osteoporosis Foundation guidelines. ${ }^{8}$

In an osteoblastic metastasis and the adjacent bone, there is an increase in osteoclast number and activity. ${ }^{9}$ Bisphosphonates are antiresorptive agents that inhibit osteoclast-mediated bone loss by decreasing their activity and attachment. ${ }^{10}$ Intravenous pamidronate and intravenous zoledronic acid are approved by the US Food and Drug Administration (FDA) for treating SREs, and until recently were the only agents used for prevention of the complications of SREs in patients with metastatic prostate cancer. However, a new agent has recently been approved by the FDA and has been shown in several studies to be as effective as bisphosphonates in preventing SREs. Denosumab, a fully human monoclonal antibody, binds to the receptor activator of nuclear factor kappa B ligand (RANK-L), a protein responsible for formation, function, and survival of osteoclasts. Denosumab prevents RANKL from activating its receptor, RANK, on the surface of osteoclasts, and reduces bone resorption, tumor-induced bone destruction, and SREs. ${ }^{11,12}$ Therefore, when discussing the future of bisphosphonates in the treatment of advanced prostate cancer, one should also include the competing agent which is approved for the same indication. This review discusses the role of antiresorptive agents bisphosphonates, and RANK-L inhibitors in the current treatment of advanced prostate cancer by examining the primary literature. It also focuses on the likely role of bisphosphonates in the treatment of advanced prostate cancer in the future.

\section{Methods}

A systemic literature review was done to identify all relevant research papers assessing the use of bisphosphonates and denosumab in the treatment of advanced prostate cancer. A summary of the results and types of trials used in the preparation of this paper is included in Table 1.

\section{Bisphosphonate trials}

Multiple clinical trials have been conducted to assess the safety and efficacy of bisphosphonates in men with prostate cancer.
These studies have evaluated the role of these agents in increasing $\mathrm{BMD}$ in men receiving ADT for nonmetastatic disease as well as for the prevention of SREs in men with metastatic disease. As already mentioned, the most common site of metastatic disease in men with advanced prostate cancer is bone, where both osteoblastic and osteoclastic activity is upregulated, increasing the probability of clinically significant bone events and necessitating the use of drug therapy for their prevention. ${ }^{13}$ These SREs, which frequently serve as the primary endpoint in evaluations of bone-targeted therapies, are most commonly defined as pathologic fracture, spinal cord compression, surgical bone repair, need for radiation therapy to bone, or introduction or change of drug therapy specifically intended for management of bone pain. ${ }^{14}$ The diagnosis and subsequent management of SREs thus has the potential to interrupt and delay the management of metastatic castrationresistant prostate cancer (mCRPC) and consequently may affect a patient's overall survivorship.

Currently, zoledronic acid is the only bisphosphonate approved for the prevention of SREs in men with mCRPC. Its approval by the FDA in February of 2002 followed completion of an international, placebo-controlled, randomized Phase III clinical trial that enrolled 643 patients. Patients were required to have good performance status as determined by Eastern Cooperative Oncology Group criteria ${ }^{15}$ and objective evidence of prostate cancer which had metastasized to bone. Patients were not allowed to be currently receiving cytotoxic chemotherapy at the time of study, but were otherwise eligible to be treated with such therapy at the discretion of their physicians after enrollment. Participants were randomized to receive zoledronic acid $4 \mathrm{mg}$ or $8 \mathrm{mg}$ (later reduced to $4 \mathrm{mg}$ due to observation of renal toxicity) or placebo every 3 weeks for 20 cycles. The primary efficacy endpoint was diagnosis of SREs on bone scans completed at 6 and 15 months after enrollment and bone surveys completed every 3 months. At least one SRE was diagnosed in $44.2 \%$ of patients in the placebo group versus $33.2 \%$ in the zoledronic acid $4 \mathrm{mg}$ arm $(95 \%$ confidence interval $[\mathrm{CI}]-20.3$ to $-1.8 ; P=0.021)$ and in $38.5 \%$ of those receiving zoledronic acid $8 \mathrm{mg}$ followed by $4 \mathrm{mg}(95 \% \mathrm{CI}-15.1$ to $3.6, P=0.222)$. Among the secondary endpoints, mean pain scores at 15 months of follow-up were higher in men receiving placebo than in those receiving zoledronic acid $(P=0.026)$, although no significant differences were observed in overall quality of life, disease progression, or performance status. Adverse drug reactions, including fatigue, anemia, myalgia, fever, and lower limb edema, were more common in patients receiving zoledronic acid, although study discontinuation rates due to adverse drug 
Table I Major trial reports for bisphosphonates and denosumab in metastatic castration-resistant prostate cancer

\begin{tabular}{|c|c|c|c|c|}
\hline Reference & Phase & $\mathbf{n}$ & Intervention & Response \\
\hline Saad et al ${ }^{14}$ & III & 643 & $\begin{array}{l}\text { Zoledronic acid } 8 \mathrm{mg} \text {, zoledronic } \\
\text { acid } 8 \mathrm{mg} / \text { reduced to } 4 \mathrm{mg} \text {, or placebo }\end{array}$ & $\begin{array}{l}\text { SRE at I } 5 \text { months: placebo, } 44.2 \% \text {; zoledronic acid } \\
8 \mathrm{mg} / 4 \mathrm{mg}: 38.5 \% \\
\text { Time to first SRE: placebo, } 32 \mathrm{I} \text { days; zoledronic acid } \\
4 \mathrm{mg} \text {, not reached; zoledronic acid } 8 \mathrm{mg} / 4 \mathrm{mg} 363 \text { days }\end{array}$ \\
\hline $\begin{array}{l}\text { Saad et al }{ }^{16} \text { (follow-up } \\
\text { of previous study) }\end{array}$ & III & 643 & Zoledronic acid $4 \mathrm{mg}$, placebo & $\begin{array}{l}\text { SRE at } 24 \text { months: placebo, } 49 \% \text {; zoledronic acid } 4 \mathrm{mg}, 38 \% \\
\text { Time to first SRE: placebo, } 32 \text { I days; zoledronic acid } \\
4 \mathrm{mg}, 488 \text { days }\end{array}$ \\
\hline Dearnaley et $\mathrm{al}^{17}$ & III & 311 & $\begin{array}{l}\text { Sodium clodronate } 2,080 \mathrm{mg} \text {, } \\
\text { placebo }\end{array}$ & $\begin{array}{l}\text { BPFS at } 2 \text { years: sodium clodronate, } 49.3 \% \text {; placebo, } 41 \% \\
\text { OS: sodium clodronate, } 37.1 \text { months; placebo, } \\
28.4 \text { months }\end{array}$ \\
\hline Ernst et $\mathrm{a}^{20}$ & NS & 227 & $\begin{array}{l}\text { Mitoxantrone } 12 \mathrm{mg} / \mathrm{m}^{2}+\text { prednisone } \\
5 \mathrm{mg} \text { + clodronate } \mathrm{I}, 500 \mathrm{mg} \text {, } \\
\text { mitoxantrone } 12 \mathrm{mg} / \mathrm{m}^{2}+\text { prednisone } \\
5 \mathrm{mg} \text { + placebo }\end{array}$ & $\begin{array}{l}\text { Palliative response: MPC, } 45 \% \text {; MPP, } 39 \% \\
\text { Median duration of response: MPC, } 6.2 \text { months; MPP, } \\
6.4 \text { months } \\
\text { SPFS: MPC, } 5.0 \text { months; MPP, } 4.0 \text { months } \\
\text { Median OS: MPC, I } 0.8 \text { months; MPP, II.5 months }\end{array}$ \\
\hline Smith et $\mathrm{a}^{29}$ & III & $\mathrm{I}, 432$ & Denosumab $120 \mathrm{mg}$, placebo & $\begin{array}{l}\text { BMFS: denosumab, } 28.4 \text { months; placebo, } 22.4 \text { months } \\
\text { TFBM: denosumab, } 32.4 \text { months; placebo, } 26 \text { months }\end{array}$ \\
\hline Fizazi et a ${ }^{30}$ & III & 1,904 & $\begin{array}{l}\text { Denosumab } 120 \mathrm{mg} \text {, zoledronic } \\
\text { acid } 4 \mathrm{mg}\end{array}$ & $\begin{array}{l}\text { Time to first SRE: denosumab }>\text { zoledronic acid by } \\
3.6 \text { months } \\
\text { Median OS: denosumab, } 19.4 \text { months; zoledronic acid, } \\
19.8 \text { months }\end{array}$ \\
\hline Smith et $\mathrm{a}^{31}$ & III & $\mathrm{I}, 468$ & Denosumab $60 \mathrm{mg}$, placebo & $\begin{array}{l}\text { BMD: denosumab > placebo by } 6.7 \% \text { at } 24 \text { months } \\
\text { New vertebral fracture (at } 36 \text { months): placebo, } 3.9 \% \text {; } \\
\text { denosumab, } 1.5 \%\end{array}$ \\
\hline $\begin{array}{l}\text { Smith et } \mathrm{a}^{33} \text { (extension } \\
\text { of previous study) }\end{array}$ & III & 1,468 & Denosumab 60 mg, placebo & Bone turnover markers: denosumab, $-90 \%$; placebo, $-3 \%$ \\
\hline Egerdie et $\mathrm{al}^{32}$ & NS & & $\begin{array}{l}\mathrm{ADT}+\text { denosumab } 60 \mathrm{mg} \\
\mathrm{ADT}+\text { placebo }\end{array}$ & Gains of BMD: denosumab, $69 \%$; placebo: $8 \%$ \\
\hline
\end{tabular}

Abbreviations: NS, not specified; SRE, skeletal-related event; BPFS, bone progression-free survival; OS, overall survival; MPC, mitoxantrone + prednisone + clodronate; MPP, mitoxantrone + prednisone + placebo; SPFS, symptomatic progression-free survival; BMFS, bone metastasis-free survival; TFMB, time to first bone metastasis; BMD, bone mineral density; ADT, androgen deprivation therapy.

reactions were similar between the two groups, suggesting that patients tolerated zoledronic acid well. ${ }^{14}$

Long-term monitoring of these patients by Saad et al showed that zoledronic acid reduced the incidence of SREs by $36 \%$ compared with placebo at 24 months. In addition, the median time to first SRE was 488 days in the zoledronic acid group versus 321 days in the placebo group $(P=0.002) .{ }^{16}$ Unfortunately, similar clinical trials that used other bisphosphonate therapies had mixed success using these agents as adjuvant cancer therapy.

Two studies have evaluated the role of oral clodronate (not available in the USA) in the treatment of men with $\mathrm{mCRPC}$. The first of these trials (MRC PR05), published in 2003, assessed 311 men randomized to clodronate 2,080 mg daily (as four $520 \mathrm{mg}$ tablets) or matching placebo. Patients were evaluated for the primary endpoint of symptomatic bone progression-free survival, defined as time from study randomization to development of symptomatic bone metastases. A total of 112 patients in the clodronate arm and 124 in the placebo arm met the criteria for bone progression-free survival, with the majority experiencing disease progression in bone rather than meeting the bone progression-free survival criterion by death. Although the authors reported a $21 \%$ reduction in risk of symptomatic bone progression or death from prostate cancer, this result was not statistically significant (95\% CI 0.61-1.02; $P=0.066$ ). Median overall survival, a secondary endpoint, was reported as 37.1 months for patients receiving clodronate versus 28.4 months for patients receiving placebo (hazards ratio [HR] 0.80; 95\% CI $0.62-1.03 ; P=0.082) .{ }^{17}$ However, a subsequent 5 -year follow-up report revealed that the men receiving clodronate did have a significant increase in overall survivorship (HR 0.77; 95\% CI 0.60-0.98; $P=0.032$ ).${ }^{18}$ Comparison with a similar study using clodronate for nonmetastatic disease demonstrated that the survival benefit is restricted to men with mCRPC. ${ }^{19}$ With regard to tolerance, $50 \%$ of patients in the clodronate arm reported at least one adverse event versus $34 \%$ of patients in the placebo arm. The most common adverse drug reactions were gastrointestinal problems ( $25 \%$ in the clodronate arm versus $26 \%$ in the placebo arm), 
increased lactate dehydrogenase levels $(20 \%$ on clodronate versus $0 \%$ on placebo), and cardiovascular problems $(10 \%$ on clodronate versus $13 \%$ on placebo).

Another study assessed the relative contribution of clodronate added to a cytotoxic regimen of mitoxantrone and prednisone to improving the frequency and duration of response in $\mathrm{mCRPC}$ patients receiving palliative chemotherapy. All patients had progressive bone disease, an Eastern Cooperative Oncology Group performance status less than 3, and had not received more than a single previous chemotherapy regimen. Mitoxantrone was dosed at $12 \mathrm{mg} / \mathrm{m}^{2}$ every 3 weeks, with the patients also receiving oral prednisone $5 \mathrm{mg}$ twice daily. The patients were additionally randomized to receive clodronate $1,500 \mathrm{mg}$ or placebo intravenously every 3 weeks. The primary endpoint in this trial was palliative response, defined as a two-point reduction in the six-point present pain intensity scale without an increase in analgesia score or evidence of disease progression, or a greater than $50 \%$ decrease in analgesia score without an increase in present pain intensity. In a total of 227 patients randomized (115 in the clodronate arm and 112 in the placebo arm), the palliative response criteria were met by $45 \%$ in the clodronate arm and $39 \%$ in the placebo arm $(P=0.54)$. Additionally, differences in secondary endpoints of overall survival, progression-free survival, and overall quality of life were not significant. ${ }^{20}$ However, these results are not unexpected given that mitoxantrone has failed to demonstrate a survival benefit in men with mCRPC in numerous clinical trials, relegating this drug to a role in the palliative management of men who are not considered candidates for taxane-based chemotherapy. ${ }^{21}$

Finally, pamidronate was evaluated in two multicenter, randomized, placebo-controlled studies (INT-05 and CGP 032) that were reported together. Inclusion criteria for these trials required patients to have skeletal or bone metastases confirmed by central radiology review and bone pain resulting from bone metastases. Patients were excluded if they had undergone a change in chemotherapy within 6 weeks of study entry, had been previously treated with bisphosphonates, or were taking drugs that affected osteoclastic bone activity. Patients were randomized to receive pamidronate $90 \mathrm{mg}$ intravenously or matched placebo every 3 weeks for 27 weeks. The primary aim of these paired studies was to investigate the ability of pamidronate to reduce pain or analgesic use, and this was assessed after 9 weeks of treatment. A total of 378 patients with mCRPC were enrolled in the two studies, which failed to demonstrate a significant difference between pamidronate and placebo because baseline pain scores were reduced in both treatment arms. However, pamidronate was well tolerated in the study, with nausea being the only adverse drug reaction and occurring in 5\% or more of patients receiving the active intervention versus placebo (bone pain, fatigue, anorexia, and constipation were also commonly reported in both treatment arms). ${ }^{22}$

Although multiple clinical trials have demonstrated the value of bisphosphonates in men with mCRPC in terms of efficacy and tolerability, practitioners may be hesitant to use these medications due to concern regarding osteonecrosis of the jaw (ONJ), a rare but serious adverse event. Defined as "the persistence of exposed bone in the oral cavity, despite adequate treatment for eight weeks, without local evidence of malignancy and no prior radiotherapy to the affected region", ${ }^{23}$ the incidence of ONJ has been reported to be $1.3 \%$ in men treated with zoledronic acid and $1.8 \%$ in men managed with denosumab (discussed below). ${ }^{23,24}$ The incidence of ONJ increases in men who have been treated with intravenous bisphosphonates and in those with a longer duration of therapy. Practitioners considering the use of bisphosphonates or denosumab in this patient population are encouraged to consider risk factors for the development of ONJ, including invasive dental procedures or a history of/concurrent oral disease. ${ }^{25}$ Aggressive pre-emptive evaluation of a patient's risk of ONJ is strongly recommended because this condition has proven to be difficult to treat and often requires discontinuation of the causative bone-modifying therapy. ${ }^{24,26,27}$

\section{Denosumab for resistant prostate cancer \\ Survival}

The efficacy of denosumab in improving bone metastasisfree survival in men with castration-resistant prostate cancer was evaluated in a randomized controlled trial. Adult men were included if they had prostate cancer, Eastern Cooperative Oncology Group performance status score $\leq 1$, and adequate organ function. The patients had previously received a bilateral orchiectomy or continuous ADT with a gonadotropin-releasing hormone agonist or antagonist for at least 6 months before study entry. In addition, they had a total serum testosterone $<50 \mathrm{ng} / \mathrm{dL}$ and were castration-resistant, with three consecutive increasing prostate-specific antigen (PSA) tests separated by $\geq 2$ weeks and the last two PSA tests $\geq 1.0 \mathrm{ng} / \mathrm{mL}$. Patients were also at high risk for bone metastasis (ie, PSA $\geq 8.0 \mathrm{ng} / \mathrm{mL}$ prior to randomization and/or PSA doubling time $\leq 10$ months). Patients received subcutaneous denosumab $120 \mathrm{mg}$ or placebo in a 1:1 allocation every 4 weeks until 660 men developed bone metastasis or died. Calcium and vitamin D supplementation was encouraged. Patients were stratified 
by PSA criteria and previous or current chemotherapy for prostate cancer. The primary endpoint was bone metastasisfree survival, as determined by first occurrence of bone metastasis (symptomatic or asymptomatic) or death from any cause. A total of 1,432 patients ( $n=716$ in each group) were included and 605 had bone metastasis ( $\mathrm{n}=165$ symptomatic; $\mathrm{n}=440$ asymptomatic). The median treatment duration was 20.2 months in the denosumab-treated patients and 19 months in the placebo-treated patients. The primary reason for discontinuation was bone metastasis (38\%). The baseline demographics were balanced between the groups. Most were white/Caucasian (84\%), resided in Europe (43\%), and aged $\geq 65$ years $(84 \%)$. Denosumab therapy was associated with bone metastasis-free survival of 4.2 months compared with placebo (29.4 months with denosumab and 25.2 months with placebo [HR $0.85 ; 95 \%$ CI $0.73-0.98 ; P=0.028$ ]). Denosumab was also associated with a $16 \%$ reduction in median time to bone metastasis (HR $0.84 ; 95 \%$ CI $0.71-0.98$; $P=0.032$ ). No significant differences were found between the groups with regard to progression of prostate cancer, overall survival, or progression-free survival. Common adverse effects were back pain, constipation, arthralgia, diarrhea, and urinary tract infections. No statistically significant differences in adverse events were identified. ${ }^{28}$

Smith et al evaluated the efficacy of denosumab and bone metastasis-free survival in men with non-mCRPC as a follow-up study. In this randomized, double-blind investigation, patients were included if they were adult men with non-mCRPC who were at high risk for development of bone metastasis (ie, PSA $\geq 8.0 \mathrm{ng} / \mathrm{mL}$ within 3 months before randomization to the study, PSA doubling time $\leq 10$ months at baseline, or both). Patients were considered resistant to castration if they had three consecutive increasing PSA tests separated by a minimum of 2 weeks and PSA $\geq 1.0$ $\mathrm{ng} / \mathrm{mL}$ for the last two measures. Patients were excluded if they received intravenous bisphosphonate therapy, and if they had extraskeletal metastases. Antineoplastic agents were allowed. Patients were randomized in a 1:1 allocation sequence to receive denosumab $120 \mathrm{mg}$ or placebo subcutaneously every 4 weeks. Treatment with calcium $(\geq 500 \mathrm{mg})$ and vitamin D ( $\geq 400 \mathrm{IU}$ ) was encouraged. Therapy was discontinued when bone metastasis occurred, and investigators then treated patients with standard therapy. The primary outcome was bone metastasis-free survival (time to first occurrence of bone metastasis [symptomatic or asymptomatic] or death from any cause). The effect of denosumab was also assessed in patients at higher risk. A total of 1,432 patients were randomly assigned to receive treatment $(n=716$ in each group). Patients in the denosumab group with a PSA doubling time $\leq 10$ months experienced a longer time to first bone metastasis than their counterparts in the placebo group, ie, 28.4 versus 2.4 months (6-month difference in favor of denosumab). The denosumab-treated patients experienced a $16 \%$ reduction in the risk of bone metastasis or death (HR $0.84 ; 95 \%$ CI $0.72-0.99 ; P=0.402$ ). In men with a PSA doubling time $\leq 6$ months, the time to first bone metastasis was 7.2 months longer in patients who received denosumab compared with those who received placebo (25.9 versus 18.7 months). In this group, denosumab therapy was associated with a $23 \%$ reduction in first bone metastasis or death (HR 0.77; 95\% CI 0.64-0.93; $P=0.006$ ). Similarly, patients with a PSA doubling time $\leq 4$ months who were receiving denosumab experienced a $29 \%$ reduction in the risk of bone metastasis or death (HR $0.71 ; 95 \%$ CI $0.56-0.90 ; P=0.004$ ). No statistically significant differences in overall survival were observed between patients when stratified by PSA doubling time. Denosumab therapy was associated with an improvement in bone metastasis-free survival in men with shorter PSA doubling times. ${ }^{29}$

\section{Skeletal events}

One randomized controlled clinical trial has investigated the efficacy of denosumab versus zoledronic acid with regard to reduction of bone metastases in patients with mCRPC. Men were included in this study if they had prostate cancer, bone metastasis, or failure while on hormonal therapy indicated by increasing PSA concentration. Final PSA concentrations were $\geq 0-4 \mu \mathrm{g} / \mathrm{L}$ within 8 weeks of randomization. Patients were stratified based on previous SREs, PSA levels ( $<10$ or $\geq 10 \mathrm{mg} / \mathrm{L}$ ), and chemotherapy received for prostate cancer in the 6 weeks before randomization. Patients were randomized to receive denosumab $120 \mathrm{mg}$ or renally adjusted zoledronic acid $4 \mathrm{mg}$ every 4 weeks. In this double-dummy trial, intravenous therapy was administered over at least 15 minutes. Appropriate doses of calcium and vitamin $\mathrm{D}$ were encouraged. The primary endpoint was time to first on-study SRE, as measured by noninferiority between agents. A total of 1,904 patients were included in the trial ( $\mathrm{n}=950$ for denosumab and $\mathrm{n}=951$ zoledronic acid). Patients were analyzed 41 months after enrollment and the median time on study therapy was 12.2 months for denosumabtreated patients and 11.2 months for zoledronic acid-treated patients. Baseline characteristics were similar between the treatment groups. The mean patient age was 71 years, the majority of patients were white (85\%), 93\% had an Eastern Cooperative Oncology Group performance status of 0-1, and $85 \%$ had a PSA $>10$ at randomization. Denosumab therapy was associated with a significant $18 \%$ reduction in 
time to first on-study SRE when compared with zoledronic acid (difference between groups, 3.6 months). Divergence between therapies was observed as early as 3 months into the study. No differences between overall survival or disease progression were observed between the groups. The adverse effect profile was also similar between the groups, with the most common adverse events being anemia, back pain, decreased appetite, nausea, fatigue, constipation, and bone pain. Denosumab was shown to be superior to zoledronic acid for reduction of adverse SREs. ${ }^{30}$

\section{Bone turnover markers}

Smith et al evaluated the efficacy of denosumab in men receiving ADT for prostate cancer in a double-blind, multicenter study. ${ }^{31}$ Eligible patients had prostate cancer and were receiving $\mathrm{ADT}$ for an expected duration of $\geq 12$ months. Men were included if they were $\geq 70$ years or $\leq 70$ years and had low BMD (below -1.0) at the lumbar spine, total hip, or femoral neck, or a history of osteoporotic fracture. Patients were stratified according to age ( $<70$ versus $\geq 70$ years) and duration of ADT ( $\leq 6$ months versus $>6$ months). Patients received denosumab $60 \mathrm{mg}$ subcutaneously or placebo every 6 months ( $n=734$ in each group). The investigators were notified of subjects with BMD levels that decreased by more than $7 \%$ during a 12 -month period and those who had a T-score below -4.0 at the total hip or lumbar spine at any time point. The primary endpoint was percent change in BMD at the lumbar spine at 24 months. Denosumab therapy was associated with a significant increase in BMD at all sites assessed. In fact, denosumab therapy increased BMD at the lumbar spine by $6.7 \%$ over that than in the placebo at 24 months ( 5.6 versus $-1.0 ; P<0.001$ ). The sustained result with denosumab was observed through 36 months. The beneficial effects of denosumab were maintained across all subgroup analyses. In a secondary endpoint analysis, denosumab therapy was associated with a significant reduction in new vertebral fractures at 36 months $3.9 \%$ in the placebo group versus $1.5 \%$ in the denosumab group; relative risk $0.38 ; 95 \%$ CI $0.19-0.78 ; P=0.006)$. Denosumab therapy was associated with increased BMD at 36 months and a decreased fracture risk.

The effect of denosumab on BMD at the lumbar spine, femoral neck, total hip, and distal radius (reported elsewhere) at 36 months was evaluated in a randomized, double-blind study in patients with non-metastatic prostate cancer receiving ADT. Men with prostate cancer who were $\geq 70$ years or $<70$ years with a history of osteoporotic fractures or a BMD T-score at any site $<1.0$ were eligible. Patients were excluded if they were receiving chemotherapy/radiotherapy, had a PSA $>5 \mathrm{mg} / \mathrm{mL}$ after receiving ADT for more than 1 month, or had a BMD T-score $<4$ at any of the measured sites. Patients were stratified by age and duration of ADT, and were randomized to receive placebo or denosumab $60 \mathrm{mg}$ subcutaneously every 6 months for up to 36 months. Vitamin D and calcium supplementation was encouraged. Baseline characteristics were well matched between the groups. Most of the patients were white (83\%), their mean age was 75 years, and most (76\%) had had $>6$ months of prior ADT. Approximately $62 \%$ of patients completed the study. Denosumab therapy was associated with a significant increase in BMD at the lumbar spine, total hip, and femoral neck of $7.9 \%, 5.7 \%$, and $4.9 \%$, respectively, compared with placebo $(P<0.0001)$ for each comparison at 36 months. Upon further evaluation, patients with lower baseline T-scores had a more profound response at all key skeletal sites; this response was significant at the lumbar spine and total hip. Denosumab was associated with improved BMD T-scores at the lumbar spine, femoral neck, and total hip. ${ }^{32}$

A randomized, double-blind, placebo-controlled trial was conducted to determine the effect of denosumab to determine the effect of denosumab on the change in bone mineral density of the lumbar spine, hip and femoral neck over 24-36 months of follow-up in patients with prostate cancer. Patients with prostate cancer were included if they were $\geq 70$ years old, or if $<70$ years of age, they had an osteoporotic fracture or a T-score $<1$ at the lumbar spine, femoral neck, or total hip. Patients were stratified by age and duration of ADT, and were randomized to receive denosumab $60 \mathrm{mg}$ or placebo subcutaneously every 6 months for 36 months. A total of 1,468 men receiving ADT for non-metastatic prostate cancer were assigned to therapy ( $n=734$ each groups). Their baseline characteristics are reported in Smith et al. ${ }^{31}$ The mean age of patients in the study was 75 years, most were white, and they had received ADT for $>6$ months. Denosumab was associated with a reduction in bone turnover markers compared with placebo. The median (quartile 1, quartile 3 ) changes in serum C-telopeptide at 6 months for denosumab and placebo were $65 \%(-80 \%,-42 \%)$ and $-7 \%(-27 \%,+31 \%)$, respectively, and this effect was maintained across all patient subgroups (eg, age and prior duration of ADT). ${ }^{33}$

The effects of denosumab on BMD in men receiving ADT for prostate cancer were assessed in a subgroup analysis reported by Badros et al. ${ }^{25} \mathrm{~A}$ total of 1,468 patients were randomized to receive denosumab $60 \mathrm{mg}$ or placebo subcutaneously every 6 months for 36 months. BMD was evaluated at the lumbar spine, total hip, and distal $1 / 3$ radius 
(additional substudy) at 36 months. Patients were evaluated according to various subgroups including age, duration/type of ADT, BMD T-scores, weight, body mass index, bone turnover markers, and vertebral fractures. At the end of the study, denosumab therapy was associated with a significant increase in BMD at the lumbar spine, total hip, and distal radius of $7.9 \%, 5.7 \%$, and $6.9 \%$, respectively, compared with placebo $(P<0.0001$ for each value). Similar results were observed across the various subgroups. No significant difference in adverse effects was observed between the groups. ${ }^{34}$

\section{Toxicities associated with denosumab therapy in prostate cancer}

The adverse effects following treatment with bisphosphonates, zoledronic acid, and denosumab were evaluated in a review of clinical trial information in patients with advanced prostate cancer. In the studies assessed, denosumab therapy was more commonly associated with cataracts, but this adverse event could not be explained. No significant changes in kidney function were observed. Hypocalcemia occurred, but was rare $(<1 \%)$. ONJ was observed in some studies. In one study, ONJ was observed in $5 \%$ of patients versus none in the placebo group. Tooth extraction $(70 \%)$, poor oral hygiene $(55 \%)$, and use of a dental appliance (48\%) were risk factors in the majority of patients diagnosed with ONJ. The majority of these patients required some form of dental intervention $(61 \%)$ or noninvasive strategies, eg, oral rinses or antibiotics (30\%). Rates of ONJ were similar between denosumab-treated and zoledronic-acid treated patients. ${ }^{35}$

\section{Discussion}

Although intravenous bisphosphonates such as zoledronic acid have been the cornerstone of treatment for SREs in patients with metastatic prostate cancer for many years, last year the FDA approved denosumab, a RANK-L inhibitor, for this indication. However, while zoledronic acid and denosumab have been shown to be equally as effective in several studies, several factors should be considered when it comes to treatment. These include ease of administration, patient preference, adverse events, and cost. Denosumab is administered subcutaneously so is usually preferred over an intravenous infusion of zoledronic acid, which takes 15 minutes and needs a dedicated space for infusion. The subcutaneous injection also eliminates concerns regarding the acute phase reaction seen with intravenous infusion of zoledronic acid. Denosumab does not require renal dosing, whereas zoledronic acid needs to be renally adjusted. However, denosumab has been linked to more severe cases of hypocalcemia when compared with zoledronic acid.
Therefore, monitoring of calcium levels as well as concurrent administration of calcium and vitamin D are important when considering use of denosumab. Further, the cost of denosumab is still higher than that of zoledronic acid. However, the overall cost of treatment seems to be similar between the two agents in the USA when one considers all the factors that go into treatment. Patient preference plays an important role in choosing one agent over the other. Some patients may prefer the shorter duration of administration with denosumab over longer treatment infusions of traditional bisphosphonates. The difference in acquisition costs of denosumab and zoledronic acid has become much greater since a generic formulation of zoledronic acid was approved by the FDA in 2013. Considering that denosumab has not been shown to improve overall survival when compared with zoledronic acid, coupled with the availability of the substantially discounted generic formulation and an otherwise similar efficacy profile, denosumab will have to justify its cost per SRE avoided. In a busy oncology practice, the cost and time spent on treating a patient and the space required will ultimately determine the choice between one agent or the other.

\section{Disclosure}

The authors declare that they do not have any financial arrangement or affiliation with any organization(s) that may have a direct interest in the subject matter of this paper. No funding was received for preparation of the manuscript.

\section{References}

1. US Cancer Statistics Work Group. United States Cancer Statistics: 1999-2010. Incidence and mortality web-based report. Atlanta, GA, USA: Department of Health and Human Services, Centers for Disease Control and Prevention and National Cancer Institute; 2013 Available from: http://www.cdc.gov/USCS. Accessed October 30, 2013.

2. Surveillance Epidemiology and End Results (SEER) Program. Turning cancer data into discover. Bethesda, MD, USA: National Cancer Institute; 2013. Available from: http://seer.cancer.gove/statfacts/html/prost.html. Accessed October 30, 2013.

3. Michaelson MD, Smith MR. The role of bisphosphonates in the management of metastatic prostate cancer. Curr Oncol Rep. 2003;5:245-249.

4. Meulenbeld HJ, van Werkhoven ED, Coenen JL, et al. Randomized phase II/III study of docetaxel with or without risedronate in patients with metastatic castration resistant prostate cancer (CRPC), The Netherlands Prostate Study (NePro). Eur J Cancer. 2012;48:2993-3000.

5. Costa L, Pierre PM. Effects of bisphosphonates on pain and quality of life in patients with bone metastases. Nat Clin Pract Oncol. 2009;6: 163-174.

6. So A, Chin J, Fleshner N, Saad F. Management of skeletal-related events in patients with advanced prostate and bone metastases: incorporating new agents into practice. Can Urol Assoc J. 2012;6:465-470.

7. Carter JA, Botteman M. Health-economic review of zoledronic acid for the management of skeletal related events in bone metastatic prostate cancer. Expert Rev Pharmacoecon Outcomes Res. 2012;12:425-437.

8. Gralow JR, Bierman JS, Farooki A, et al. NCCN Task Force Report: Bone Health in Cancer Care. J Natl Compr Canc Netw. 2009;7:S1-S35. 
9. Lee RJ, Saylor PJ, Smith MR. Treatment and prevention of bone complications from prostate cancer. Bone. 2011;48:88-95.

10. Bottiglieri S, Adams V. Pharmacologic prevention of skeletal-related events in cancer patients. Orthopedics. 2010;33:577-580.

11. Dranitsaris G, Hatzimichael E. Interpreting results from oncology clinical trials: a comparison of denosumab to zoledronic acid for the prevention of skeletal-related events in cancer patients. Support Care Cancer. 2012;20:1353-1360.

12. Spence MM, Hui R, Chan J, Schottinger JE. Risk of skeletal-related events in patients with advanced prostate cancer treated with pamidronate or zoledronic acid. Ann Pharmacother. 2010;44:1384-1388.

13. Morgans A, Smith M. Bone targeted agents: preventing skeletal complications in prostate cancer. Urol Clin North Am. 2012;39: $533-546$.

14. Saad F, Gleason D, Murray R, et al. A randomized, placebo-controlled trial of zoledronic acid in patients with hormone-refractory metastatic prostate carcinoma. J Natl Cancer Inst. 2002;94:1458-1468.

15. Oken M, Creech R, Tormey D, et al. Toxicity and Response Criteria of the Eastern Cooperative Oncology Group. Am J Clin Oncol. 1982;5: 649-655.

16. Saad F, Gleason D, Murray R, et al. Long-term efficacy of zoledronic acid for the prevention of skeletal complications in patients with metastatic hormone-refractory prostate cancer. J Natl Cancer Inst. 2004;96: 879-882.

17. Dearn D, Sydes M, Mason M, et al. A double-blind, placebo-controlled, randomized trial of oral sodium clodronate for metastatic prostate cancer (MRC PR05 trial). J Natl Cancer Inst. 2003;95:1300-1311.

18. Dearnaley D, Mason M, Parmar M, et al. Adjuvant therapy with oral sodium clodronate in locally advanced and metastatic prostate cancer: long-term overall survival results from the MRC PR04 and PR05 randomized controlled trials. Lancet Oncol. 2009;10:872-876.

19. Mason M, Sydes M, Glaholm J, et al. Oral sodium clodronate for nonmetastatic prostate cancer - results of a randomized double-blind placebo-controlled trial: Medical Research Council PR04 (ISRCTN61384873). J Natl Cancer Inst. 2007;99:765-776.

20. Ernst D, Tannock E, Winquist P, et al. Randomized, double-blind, controlled trial of mitoxantrone/prednisone and clodronate versus mitoxantrone/prednisone and placebo in patients with hormone-refractory prostate cancer and pain. J Clin Oncol. 2003;21:3335-3342.

21. National Comprehensive Cancer Network. Prostate Cancer (Version 4.2013). Available from: http://www.nccn.org/professionals/ physician gls/pdf/prostate.pdf. Accessed: October 21, 2013.

22. Small E, Smith M, Seaman J, et al. Combined analysis of two multicenter, randomized, placebo-controlled studies of pamidronate disodium for the palliation of bone pain in men with metastatic prostate cancer. J Clin Oncol. 2003;21:4277-4284.
23. [No authors listed]. American Association of Oral and Maxillofacial Surgeons. Position Paper on bisphosphonate-related osteonecrosis of the jaw. J Oral Maxillofac Surg. 2007;65:369-376.

24. Saad F, Brown J, Van Poznak C, et al. Incidence, risk factors and outcomes of osteonecrosis of the jaw: integrated analysis from three blinded active-controlled Phase III trials in cancer patients with bone metastases. Ann Oncol. 2012;23:1341-1347.

25. Badros A, Weikel D, Salama A, et al. Osteonecrosis of the jaw in multiple myeloma patients: clinical features and risk factors. J Clin Oncol. 2006;24:945-952.

26. Bekker P, Holloway D, Rasmussen A, et al. A single-dose placebocontrolled study of AMG 162, a fully human monoclonal antibody to RANKL, in postmenopausal women. $J$ Bone Miner Res. 2004;19: 1059-1066.

27. McClung M, Lewiecki E, Cohen S, et al. Denosumab in postmenopausal women with low bone mineral density. N Engl J Med. 2006;354: 821-831.

28. Smith MR, Saad F, Coleman R, et al. Denosumab and bone metastasisfree survival in men with castration-resistant prostate cancer: results of a global phase 3, randomized, placebo-controlled trial. Lancet. 2012;379: $39-46$.

29. Smith MR, Saad F, Oudard S, et al. Denosumab and bone metastasis-free survival in men with nonmetastatic castration-resistant prostate cancer: exploratory analyses by baseline prostate-specific antigen doubling time. J Clin Oncol. 2013;30:3800-3806.

30. Fizazi K, Carducci M, Smith M, et al. Denosumab versus zoledronic acid for treatment of bone metastases in men with castration-resistant prostate cancer: a randomized, double-blind study. Lancet. 2011;377: 813-822.

31. Smith MR, Egerdie B, Hernandez N, et al. Denosumab in men receiving androgen-deprivation therapy for prostate cancer. $N$ Engl $J$ Med. 2009;361:745-755.

32. Egerdie B, Saad F, Smith MR, et al. Responder analysis of the effects of denosumab on bone mineral density in men receiving androgen deprivation therapy for prostate cancer. Prostate Cancer Prostatic Dis. 2012;15:308-312.

33. Smith MR, Saad F, Egerdie B, et al. Denosumab and changes in bone turnover markers during androgen deprivation therapy for prostate cancer. J Bone Miner Res. 2011;26:2827-2833.

34. Smith MR, Saad F, Egerdie B, et al. Effects of denosumab on bone mineral density in men receiving androgen deprivation therapy for prostate cancer. J Urol. 2009;182:2670-2675.

35. Gartrell BA, Coleman RE, Fizazi K, et al. Toxicities following treatment with bisphosphonates and receptor activator of nuclear factor- $\mathrm{\kappa B}$ ligand inhibitors in patients with advanced prostate cancer. Eur Urol. 2014;65:278-286.
Cancer Management and Research

\section{Publish your work in this journal}

Cancer Management and Research is an international, peer-reviewed open access journal focusing on cancer research and the optimal use of preventative and integrated treatment interventions to achieve improved outcomes, enhanced survival and quality of life for the cancer patient. The journal welcomes original research, clinical \& epidemiological

\section{Dovepress}

studies, reviews \& evaluations, guidelines, expert opinion \& commentary, case reports \& extended reports. The manuscript management system is completely online and includes a very quick and fair peerreview system, which is all easy to use. Visit http://www.dovepress.com/ testimonials.php to read real quotes from published authors. 